\title{
Six-minute walking versus shuttle walking: responsiveness to bronchodilation in chronic obstructive pulmonary disease
}

\author{
Véronique Pepin, Julie Brodeur, Yves Lacasse, Julie Milot, Pierre LeBlanc, François Whittom, François \\ Maltais
}

See end of article for authors' affiliations

\section{Correspondence to:} Dr François Maltais, Centre de Pneumologie, Hốpital Laval, 2725 Chemin SteFoy, Ste-Foy, Québec, GIV 4G5, Canada; francois. maltais@med.ulaval.ca

Received 15 May 2006 Accepted

27 September 2006

Published Online First

10 November 2006
Thorax 2007:62:291-298 doi: 10.1136/thx.2006.065540

Background: The responsiveness of the endurance shuttle walk to functional changes following bronchodilation has recently been reported. The current literature suggests that the 6 min walking test (6MWT) is less responsive to bronchodilation than the endurance shuttle walk.

Aim: To compare bronchodilator-induced changes in exercise performance with the 6MWT and the endurance shuttle walk.

Methods: In a randomised, double-blind, placebo-controlled, crossover trial, 14 patients with chronic obstructive pulmonary disease (forced expiratory volume in $1 \mathrm{~s}\left(\mathrm{FEV}_{1}\right) 50(8) \%$ predicted) completed two $6 \mathrm{MWTs}$ and two endurance shuttle walks, each preceded by nebulised placebo or $500 \mu \mathrm{g}$ ipratropium bromide. Cardiorespiratory parameters were monitored during each walking test with a portable telemetric gas analyser. Quadriceps twitch force was measured by magnetic stimulation of the femoral nerve before and after each walking test.

Results: The 6 min walking distance did not change significantly after bronchodilation despite a significant increase in $\mathrm{FEV}_{1}$ of $0.18(0.09)$ litres $(\mathrm{p}<0.001)$. A similar change in $F E V_{1}(0.18(0.12)$ litres, $p<0.001)$ was associated with a significant improvement in the distance walked on the endurance shuttle walk ( $\Delta$ distance ipratropium bromide - placebo $=144$ (219) $\mathrm{m}, \mathrm{p}=0.03)$. Quadriceps muscle fatigue was infrequent $(<15 \%$ of patients) after both walking tests.

Conclusion: The endurance shuttle walk is more responsive than the 6MWT for detecting changes in exercise performance following bronchodilation.

R

ecent management guidelines recommend that treatments for chronic obstructive pulmonary disease (COPD) should be evaluated not only for their effects on lung function, but also for their impact on exercise capacity. ${ }^{1}$ Exercise testing is a useful evaluative tool, allowing standardised measurement of exertional dyspnoea and exercise tolerance. ${ }^{1}$ However, little is known about the responsiveness of the different exercise tests to pharmacological treatments in COPD.

We recently conducted a trial comparing two exercise teststhe constant work rate cycling test and the endurance shuttle walk-for their ability to detect changes in functional status following acute bronchodilation in patients with COPD. ${ }^{2}$ Our results showed that the endurance shuttle walk identified larger and more consistent improvements in exercise performance than the constant work rate cycling test following bronchodilation. Our findings also indicated that the cardiorespiratory response was similar for the two tests, while the presence of quadriceps muscle fatigue was more frequent and more pronounced after cycling than after walking. Given that leg fatigue may prevent bronchodilation from translating into further improvement in exercise tolerance, ${ }^{3}$ we concluded that the endurance shuttle walk was a particularly well designed evaluative tool for detecting changes in functional status following bronchodilation in COPD.

The current literature suggests that the 6 min walking test (6MWT) may not be as responsive to bronchodilation as the endurance shuttle walk. ${ }^{4-11}$ In general, only modest changes in 6 min walking distance (6MWD) of little clinical significance have been reported following acute bronchodilation in COPD. ${ }^{4-}$ ${ }^{11}$ The underlying physiological mechanisms for the apparent lack of sensitivity of the 6MWT to acute bronchodilation have yet to be fully explained. It is unclear why the 6MWT and the endurance shuttle walk do not show the same responsiveness to bronchodilation.
One fact worth highlighting is that these two functional walks have different designs. The 6MWT is a self-paced test (ie, patients determine their own walking speed) of a fixed duration. In contrast, the endurance shuttle walk is an externally-paced test (ie, walking speed is dictated to patients) of an indefinite duration. Improvements in performance are therefore achieved differently for the two tests. Patients have to increase walking speed to cover more distance on the 6MWT, while they have to increase endurance time to achieve the same outcome on the endurance shuttle walk. We hypothesised that these differences in test design, and their associated physiological consequences, are responsible for the differences in responsiveness to bronchodilation seen with the 6MWT and the endurance shuttle walk.

The present study was undertaken in patients with COPD (1) to compare directly the changes in exercise performance detected by the 6MWT with those detected by the endurance shuttle walk in response to the administration of a bronchodilator, and (2) to provide a physiological understanding of the responsiveness of the tests to change by examining the cardiorespiratory response and the degree of quadriceps muscle fatigue elicited by each test.

\section{METHODS \\ Subjects}

Sixteen patients volunteered to participate in the study. Two patients were excluded after the first visit, one because of a

Abbreviations: COPD, chronic obstructive pulmonary disease; $\mathrm{FEV}_{1}$, forced expiratory volume in $1 \mathrm{~s}$; FVC, forced vital capacity; 6MWD, 6 min walking distance; $6 \mathrm{MWT}, 6$ min walking test; MVV, maximum voluntary ventilation; $\mathrm{SpO}_{2}$, oxygen saturation; $\mathrm{V}_{2} \mathrm{CO}_{2}$, carbon dioxide production; $\dot{\mathrm{V}}$, minute ventilation; $\dot{\mathrm{V}}_{2}$, oxygen consumption 
respiratory exacerbation and the other because of an inability to comply with the exercise testing procedure. Thus, 14 patients completed the study protocol. Four of these patients had participated in a previous investigation comparing the constant work rate cycling test and the endurance shuttle walk. ${ }^{2}$ This sample size was based on a previous investigation completed in our laboratory in which a statistically significant improvement in endurance shuttle walking distance was obtained in response to bronchodilation in a similar number of patients. ${ }^{2}$

Inclusion criteria were as follows: (1) moderate to severe COPD according to the GOLD guidelines (class II and III ${ }^{1}$ ); (2) age $>50$ years; (3) smoking history $>10$ pack-years; (4) no COPD exacerbation within the preceding 4 weeks; (5) no history of asthma; (6) no need for supplemental oxygen during exercise; and (7) no other active condition that could influence exercise tolerance. Patients receiving tiotropium bromide were excluded from the study. The research protocol was approved by the institutional ethics committee and signed informed consent was obtained from each subject.

\section{Study design}

The study required five visits to the research facility. The first visit included pulmonary function testing, incremental shuttle walking and familiarisation with the two walk tests (6MWT and endurance shuttle walk). The familiarisation consisted of completing two full tests for the 6MWT and several minutes at the target speed for the endurance shuttle walk. At the following four visits, subjects completed two 6MWTs and two endurance shuttle walks in a random order, at the rate of one test per visit. Each test was preceded by administration of nebulised placebo or $500 \mu \mathrm{g}$ ipratropium bromide in a randomised and double-blind fashion. Subjects were asked to withdraw from short-acting $\beta_{2}$ agonists $(6 \mathrm{~h})$, short-acting anticholinergics $(6 \mathrm{~h})$, long-acting $\beta_{2}$ agonists $(12 \mathrm{~h})$ and theophyllines $(24 \mathrm{~h})$ before these visits. Study visits were separated by at least $48 \mathrm{~h}$ but no more than 1 week. Subjects were scheduled to attend at the same time of day throughout the study. More details about the experimental design are provided in fig El in the online data supplement available at http://thorax.bmj.com/supplemental.

\section{Pulmonary function testing}

Spirometric data were obtained according to recommended techniques $^{12}$ and the results were compared with predicted normal values from the European Community for Coal and Steel/European Respiratory Society. ${ }^{13}$

\section{Incremental shuttle walk}

Peak walking capacity was first determined by incremental shuttle walking. ${ }^{14}$ More details about this test can be found in the online data supplement available at http://thorax.bmj.com/ supplemental.

\section{Endurance shuttle walk}

The endurance shuttle walk was performed in an enclosed corridor on a flat course $10 \mathrm{~m}$ in length, as previously described by Revill and colleagues. ${ }^{15}$ After a 2 min warm-up, the walking speed was set at the speed corresponding to $80 \%$ of peak oxygen consumption $\left(\dot{\mathrm{V}}_{2}\right)$, as predicted from the incremental shuttle walk. Before each test, patients were instructed to walk for as long as possible at the speed dictated by the auditory signal. Patients were notified that no further encouragement would be provided to them during the test. This was done to avoid any potential confounding effect on their performance. ${ }^{16}$

\section{Six-minute walking test}

The 6MWT was completed in an enclosed corridor on a flat course $30 \mathrm{~m}$ in length according to the procedures recommended by the American Thoracic Society (ATS). ${ }^{17}$ More details about this test can be found in the online data supplement available at http://thorax.bmj.com/supplemental.

\section{Physiological measures}

Cardiorespiratory parameters $\left(\dot{\mathrm{V}}_{2}\right.$, carbon dioxide production $\left(\dot{\mathrm{V}} \mathrm{CO}_{2}\right)$, minute ventilation ( $\left.\dot{\mathrm{VE}}\right)$, respiratory rate and heart rate) were monitored breath-by-breath with a portable telemetric system (K4b, ${ }^{2}$ Cosmed, Rome, Italy). More details about this system are available in the online data supplement available at http://thorax.bmj.com/supplemental. Oxygen saturation $\left(\mathrm{Spo}_{2}\right)$ was measured at rest, every $60 \mathrm{~m}$ during the tests, and at endexercise by pulse oximetry (OSM2 Hemoximeter; Radiometer, Copenhagen, Denmark).

Quadriceps twitch force was measured before and immediately after each test using magnetic stimulation of the femoral nerve as previously described by Saey and colleagues. ${ }^{3}$ Contractile muscle fatigue was defined as a post-exercise reduction in quadriceps twitch force of more than 15\% from the resting value. ${ }^{3}$ Further details on this methodology are available in the online data supplement and in fig E2 available at http://thorax.bmj.com/supplemental.

\section{Subjective measures}

Dyspnoea was evaluated at rest, every $60 \mathrm{~m}$ during the tests, and at end-exercise with the modified 10-point Borg scale. ${ }^{18}$ Perception of leg fatigue was evaluated at rest and at endexercise with the same scale. Patients were asked to identify the main limiting factor that precluded them from walking faster (6MWT) or longer (endurance shuttle walk).

\section{Statistical analyses}

The results are reported as mean (SD). The distance walked on the endurance shuttle walk excluded the 2 min warm-up period. The extent to which the two walking tests (6MWT and endurance shuttle walk) were able to detect changes in exercise performance (walking distance) between the two conditions (placebo and ipratropium bromide) was evaluated with repeated-measures ANOVA, where both treatment and carryover effects were examined. In addition, a standardised response mean (mean change in distance walked from placebo to ipratropium bromide/standard deviation of change) was computed for each walking test. The degree of association between baseline $\mathrm{FEV}_{1}$, bronchodilator-induced change in $\mathrm{FEV}_{1}$, mean walking distance (placebo and ipratropium bromide) and bronchodilator-induced changes in walking distance was examined with Pearson correlations.

Table 1 Baseline sample characteristics $(N=14)$

\begin{tabular}{|c|c|c|}
\hline & Mean (SD) & Range \\
\hline Age (years) & $64(6)$ & $51-73$ \\
\hline Height $(\mathrm{m})$ & $1.65(0.10)$ & $1.47-1.81$ \\
\hline Weight (kg) & $73(20)$ & $46-106$ \\
\hline BMI $\left(\mathrm{kg} / \mathrm{m}^{2}\right)$ & $27(5)$ & $18-34$ \\
\hline $\mathrm{FEV}_{1}$ (litres) & $1.31(0.39)$ & $0.78-2.00$ \\
\hline $\mathrm{FEV}_{1}$ (\% predicted) & $50(7)$ & $39-64$ \\
\hline FVC (litres) & $2.83(0.61)$ & $1.66-3.82$ \\
\hline $\mathrm{FEV}_{1} / \mathrm{FVC}(\%)$ & $46(7)$ & $34-55$ \\
\hline ISW distance $(\mathrm{m})$ & $514(135)$ & $340-790$ \\
\hline$\dot{\mathrm{V}}_{2}$ peak $(\mathrm{l} / \mathrm{min})$ & $1.81(0.65)$ & $0.89-3.48$ \\
\hline$\dot{\mathrm{VO}}_{2}$ peak $(\mathrm{ml} / \mathrm{kg} / \mathrm{min})$ & $25(6)$ & $16-33$ \\
\hline
\end{tabular}

$\mathrm{BMI}$, body mass index; $\mathrm{FEV}_{1}$, forced expiratory volume in $1 \mathrm{~s}$; FVC, forced vital capacity; ISW, incremental shuttle walk; $\mathrm{VO}_{2}$, oxygen uptake. 
Cardiorespiratory kinetics were compared between both walking tests and both testing conditions using a crossover ANOVA with repeated measurements within treatment periods. ${ }^{19}$ When a statistically significant interaction with time was obtained (eg, test ${ }^{\star}$ time), post-hoc tests were performed using Fisher's protected least significant difference (LSD) with Bonferroni corrections to identify the time points at which the differences occurred. Peak cardiorespiratory values were compared across the four testing conditions with repeated-measures ANOVA. The difference between resting and post-exercise quadriceps twitch force was evaluated for each walking test with paired $t$ tests. The degree of quadriceps muscle fatigue was compared between both walking tests and both testing conditions with repeated-measures ANOVA. The locus of symptom limitation was compared between the two walking tests using a Wilcoxon signed rank test. The level of statistical significance was set at $\mathrm{p}<0.05$.

\section{RESULTS}

\section{Subjects}

The baseline characteristics of the study group are presented in table 1. Patients had stage II to stage III COPD, according to GOLD classification, and variable exercise capacities, as indicated by the wide range of performances on the incremental shuttle walk.

\section{Pulmonary function}

$\mathrm{FEV}_{1}$ values obtained before and after nebulisation before the two 6MWT and the two endurance shuttle walks are shown in fig 1. Pre-nebulisation values were similar across the four testing conditions. $\mathrm{FEV}_{1}$ remained unchanged after both placebo nebulisations, while a similar and significant increase was observed with ipratropium bromide before the two tests (0.18 (0.09) litres for the 6MWT and $0.18(0.12)$ litres for the endurance shuttle walk).

\section{Walking distance}

Individual data and group mean for the distance walked in the four walking tests are shown in fig 2. Baseline walking distance and test duration (ie, with placebo) were significantly greater for the 6MWT than for the endurance shuttle walk (walking distance 553 (68) vs 420 (183) $\mathrm{m}, \mathrm{p}<0.05$, for the 6MWT; walking time 360 (0) vs 253 (112) s, p<0.01, for the endurance
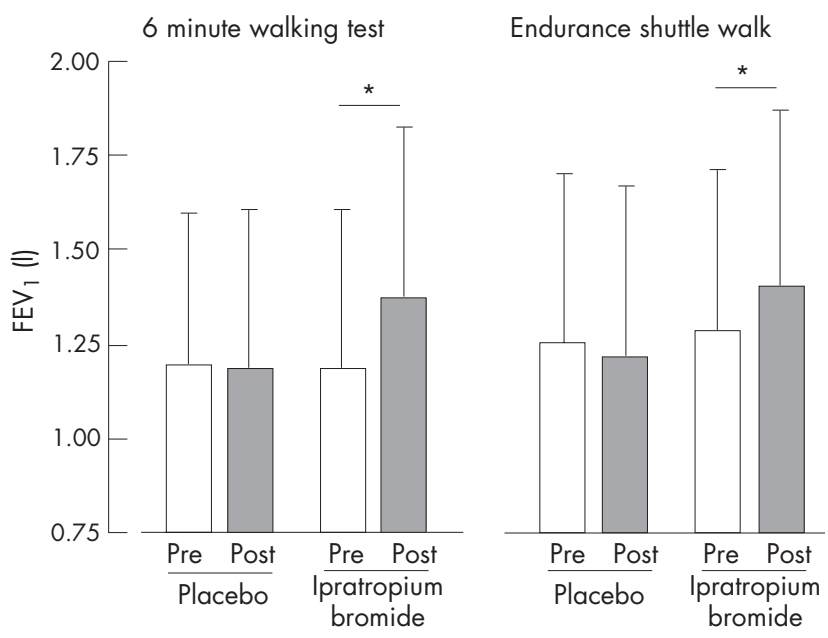

Figure 1 Pre-nebulisation (open bars) and post-nebulisation (shaded bars) values for forced expiratory volume in $1 \mathrm{~s}\left(\mathrm{FEV}_{1}\right)$ with placebo and ipratropium bromide for the 6 min walking test (6MWT) and the endurance shuttle walk. Values are expressed as mean (SD). * $p<0.001$. shuttle walk). Estimated walking speed was similar between the two walking tests. Patients achieved $88(8) \%$ of their predicted $6 \mathrm{MWD} .^{20}$ On average, the distance walked on the endurance shuttle walk increased significantly with bronchodilation $(\Delta$ distance walked ipratropium bromide - placebo $=$ 144 (219) m (95\% CI 30 to 259)). In contrast, 6MWD did not increase significantly with ipratropium bromide ( $\Delta$ distance walked ipratropium bromide - placebo $=7$ (17) $\mathrm{m}(95 \% \mathrm{CI}$ -1 to 16)). There was no carryover effect for either walking test. The individual data indicate that 9 of the 14 patients (64\%) improved their performance on the endurance shuttle walk with bronchodilation, whereas performances on the 6MWT remained remarkably constant between the two conditions. The standardised response mean (magnitude of change/standard deviation of change) was larger for the endurance shuttle walk than for the 6MWT (0.66 and 0.42, respectively).

The mean walking distances (placebo and ipratropium bromide) and the changes in walking distance with bronchodilation did not correlate significantly; this was true both for the 6MWT $(r=0.14, p=0.63)$ and the endurance shuttle walk $(\mathrm{r}=0.41, \mathrm{p}=0.15)$. Finally, improvement in 6MWD and shuttle walking distance after bronchodilation did not correlate with changes in $\mathrm{FEV}_{1}$.

\section{Physiological response}

Figure 3 shows the time course and end-exercise values for $\dot{\mathrm{V}}_{2}$, $\dot{\mathrm{VE}}, \dot{\mathrm{V}} \mathrm{E} / \mathrm{maximal}$ voluntary ventilation (MVV), respiratory rate, dyspnoea and heart rate during the 6MWT and the endurance shuttle walk with placebo. The initial rise was significantly faster for the endurance shuttle walk than for the 6MWT. During the endurance shuttle walk, $\dot{V}$, respiratory rate and heart rate quickly approached values achieved on the maximal incremental shuttle walk, while these parameters remained at submaximal levels throughout the 6MWT.

The cardiorespiratory response to 6 min walking with placebo and ipratropium bromide is shown in fig $4 . \dot{\mathrm{V}}_{2}$ showed a steady-state profile after the third minute of both 6MWTs, as previously reported. ${ }^{21}{ }^{22}$ Cardiorespiratory kinetics were remarkably similar for the two tests, suggesting that both 6 MWTs were performed at a similar pace. This physiological observation was supported by the data related to the estimated walking speed, which indicated that patients replicated the same walking pattern during the two 6MWTs. The cardiorespiratory response to endurance shuttle walking was also similar between the placebo and ipratropium bromide conditions, but patients were able to sustain the workload for a longer duration with ipratropium bromide (fig 5). Interestingly, end-exercise dyspnoea was similar between the two endurance shuttle walks despite the fact that a higher $\dot{\mathrm{V}} \mathrm{E}$ was reached with ipratropium bromide than with placebo. Finally, neither test elicited a significant fall in quadriceps twitch force. Quadriceps muscle fatigue occurred in less than 15\% of patients after both walking tests.

\section{Subjective response}

The perception of dyspnoea was significantly higher for the endurance shuttle walk than for the 6MWT from the fourth measurement $(180 \mathrm{~m})$ up until the end of the tests. The locus of symptom limitation was similar between the two walking tests. Dyspnoea was cited as the main limiting factor by 9 patients with the 6MWT and 11 patients with the endurance shuttle walk; 11 of the 14 patients found the endurance shuttle walk to be more difficult than the 6MWT.

\section{DISCUSSION}

The aim of this study was to compare two field walking tests, the 6MWT and the endurance shuttle walk, with respect to 


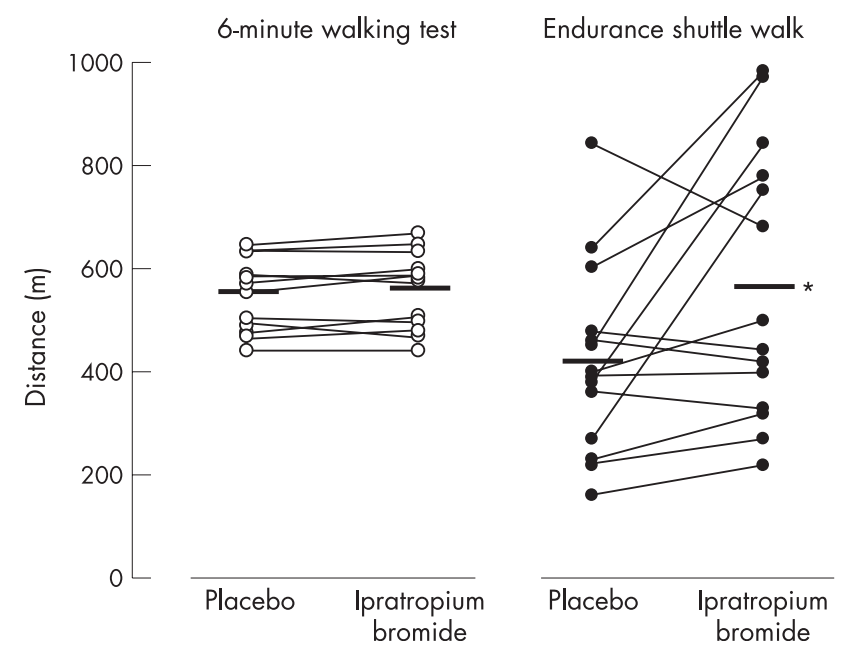

Figure 2 Individual data for changes in distance walked with placebo and with ipratropium bromide for the 6 min walking test and the endurance shuttle walk. The group mean for each experimental condition is represented by the horizontal bar. ${ }^{*} p=0.028$. their ability to detect functional changes after bronchodilation in patients with COPD. Our results show that the endurance shuttle walk is more responsive to the acute effects of bronchodilation than the 6MWT in this patient population. Given the wide use of field walking tests as evaluative tools, this finding has important implications for future clinical trials assessing the functional impact of bronchodilation in patients with COPD.

In the present study, 6MWD did not improve significantly with ipratropium bromide. Previous investigations of the effect of anticholinergic agents on 6MWD have yielded inconsistent results. ${ }^{4523-26}$ In one large multicentre clinical trial, no significant change in 6MWD was observed after 12 weeks of treatment with ipratropium bromide. ${ }^{5}$ In contrast, other smaller investigations obtained statistically significant improvements in 6MWD in response to single doses of oxitropium bromide, $^{4225}$ ipratropium bromide ${ }^{23}$ and a combination of salbutamol and ipratropium bromide. ${ }^{26}$ In these studies, improvements in 6MWD have ranged from $6 \mathrm{~m}$ to $39 \mathrm{~m}$ after bronchodilation with anticholinergic agents, which is consistent in magnitude with the change obtained in the present study (7 (17) $\mathrm{m})$. Considering that the minimal clinically important difference in 6MWD is $54 \mathrm{~m}$ (95\% CI 37 to 71$),{ }^{27}$ the
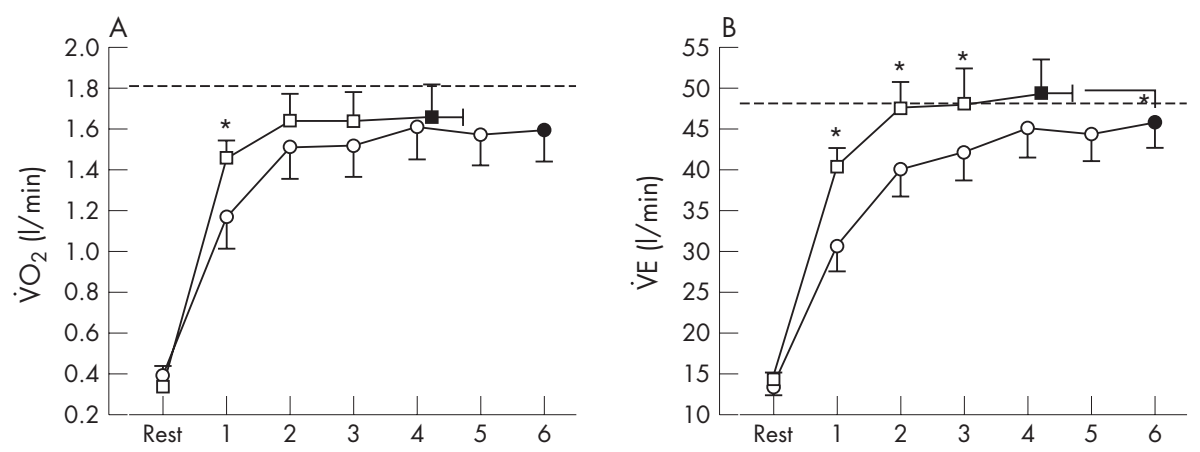

Figure 3 Cardiorespiratory response during the 6 min walking test (6MWT, circles) and the endurance shuttle walk (squares) with placebo. Time course (open symbols) and end-exercise (closed symbols) values are shown for $(\mathrm{A})$ oxygen consumption $\left(\mathrm{VO}_{2}\right)$, (B) minute ventilation (VE), (C) VE/maximal voluntary ventilation (MVV), (D) respiratory rate (RR), (E) dyspnoea, and (F) heart rate (HR). The dashed line represents the peak value achieved on the incremental shuttle walk. Values are mean (SE). ${ }^{*} \mathrm{p}<0.05 ; \mathrm{\dagger p}<0.01$; $\neq \mathrm{p}<0.001$.
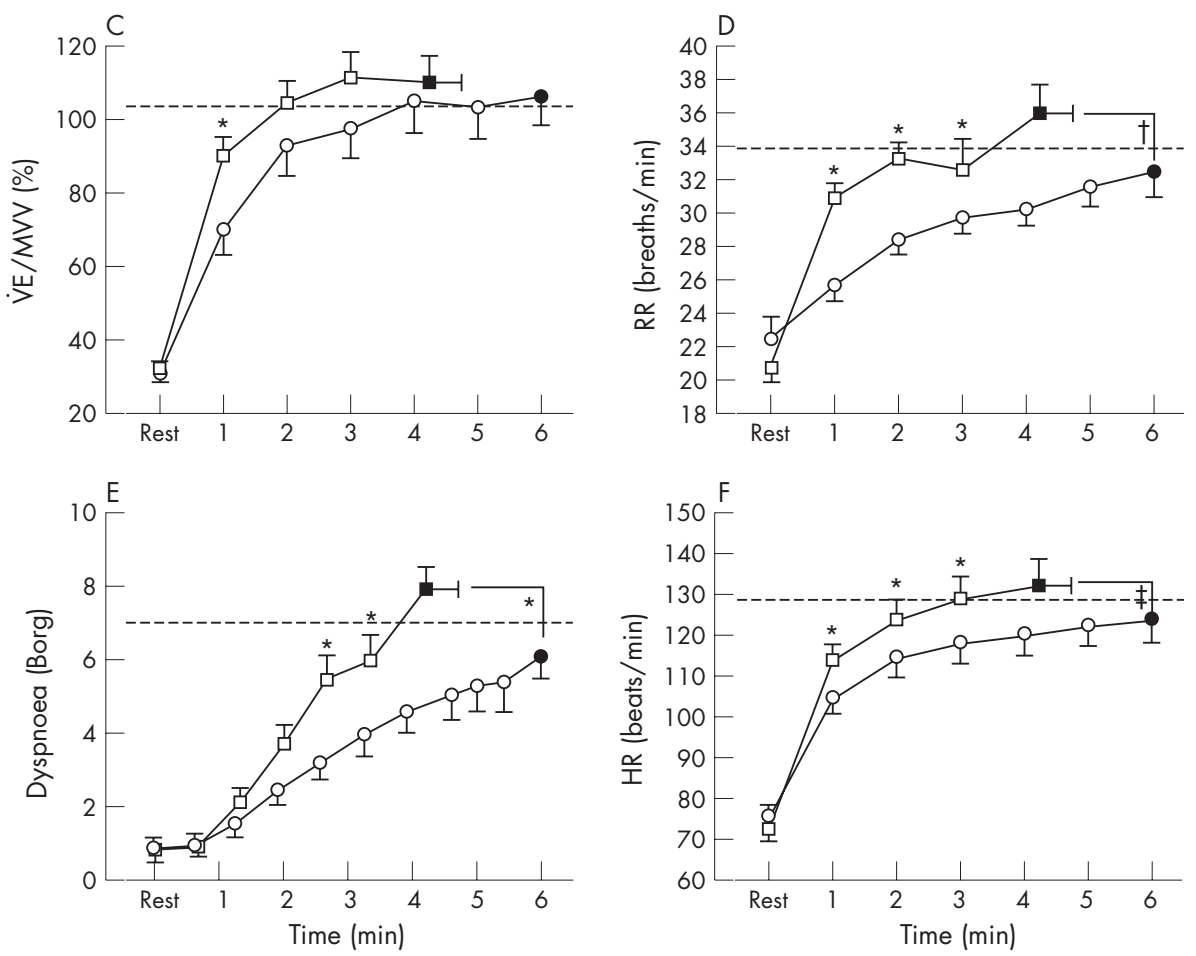

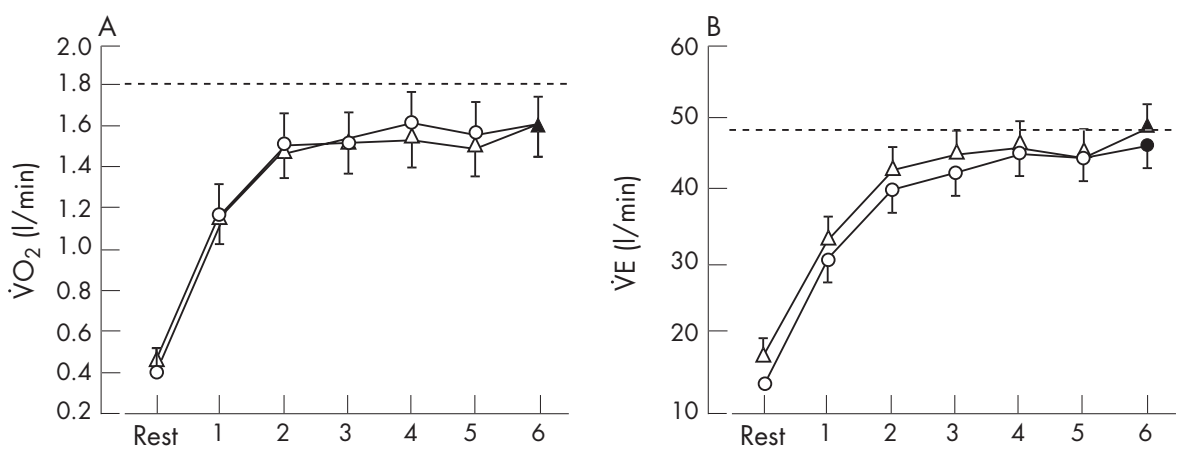

Figure 4 Cardiorespiratory response during the $6 \mathrm{~min}$ walking test (6MWT) under placebo (circles) and ipratropium bromide (triangles). Time course (open symbols) and end-exercise (closed symbols) values are shown for $(\mathrm{A})$ oxygen consumption $\left(\mathrm{V}_{2}\right),(\mathrm{B})$ minute ventilation (VE), (C) VE/maxima voluntary ventilation (MVV), (D) respiratory rate (RR), (E) dyspnoea, and (F) heart rate (HR). The dashed line represents the peak value achieved on the incremental shuttle walk. Values are mean (SE).
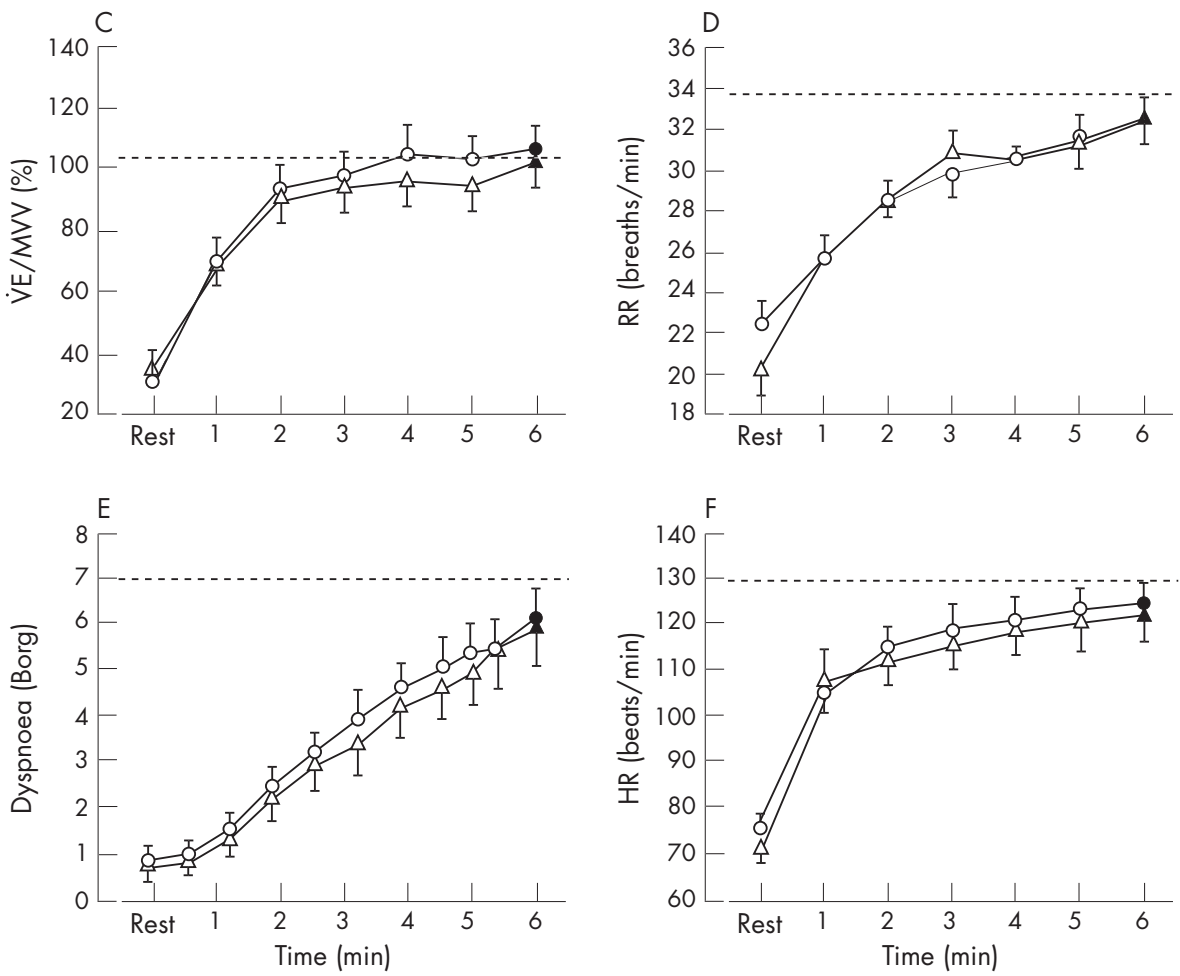

clinical significance of the improvement in 6MWD with acute bronchodilation is questionable.

Previous studies reporting significant improvements in 6MWD in response to bronchodilation have been conducted in patients with baseline 6MWD ranging from 237 to $490 \mathrm{~m}^{4}{ }^{23-}$ ${ }^{26}$ This may suggest that the lack of responsiveness observed with the 6MWT in the present study could be related to the presence of a ceiling effect because of a relatively high baseline 6MWD (553 (68) m). This possibility was considered, but was not supported by our data. First, although 6MWD was relatively well preserved in our patients, it represented $88 \%$ of normal predicted values, indicating that there was room for further improvement. In addition, there was no correlation between mean 6MWD and improvement in 6MWD with bronchodilation, indicating that there was no systematic bias in the magnitude of bronchodilator-induced improvement in 6MWD according to mean performance. Thus, patients with high performances on the 6MWT did not show lesser gains in 6MWD than patients with lower performances.

Little is known about the sensitivity of the endurance shuttle walk to bronchodilation. To our knowledge, the present study is only the second one to report its responsiveness to bronchodilation. In a previous investigation ${ }^{2}$ we showed that the distance walked on the endurance shuttle walk improved significantly with ipratropium bromide, that the test was able to detect an improvement in exercise performance in $82 \%$ of patients, and that its standardised response mean (signal to noise ratio) was greater than that of the constant work rate cycling test. Similarly, in the present study, the distance walked on the endurance shuttle walk increased significantly in response to ipratropium bromide. The test captured an improvement in exercise performance in $64 \%$ of the patients and its standardised response mean was greater than that of the 6MWT. The standardised response mean of the endurance shuttle walk was somewhat lower in the present study than in our previous investigation (0.66 vs 0.94). The reasons underlying this observation remain unclear. Subjects had slightly less severe airflow obstruction and higher baseline functional capacity in our previous investigation, supporting the notion that the lower responsiveness to bronchodilation in the present study was not due to the relatively well preserved lung function and functional status. Nevertheless, when the data from both studies are combined, the resulting standardised response mean for the endurance shuttle walk is 0.82 , which is considered large. ${ }^{28}$

Two physiological mechanisms were explored to explain differences in sensitivity to bronchodilation between the 6MWT 

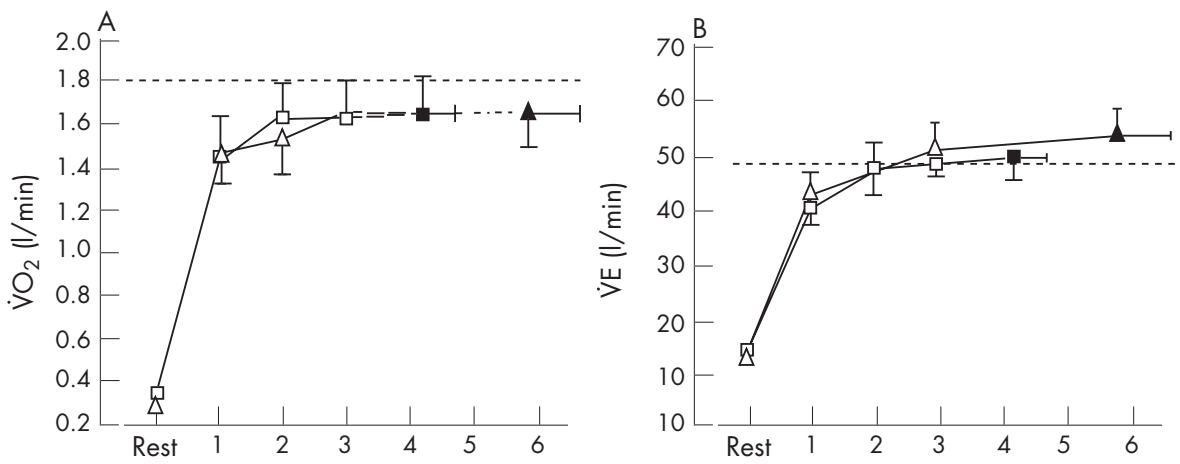

Figure 5 Cardiorespiratory response during the endurance shuttle walk under placebo (squares) and ipratropium bromide (triangles). Time course (open symbols) and end-exercise (closed symbols) values are shown for (A) oxygen consumption $\left(\mathrm{V}_{2}\right),(\mathrm{B})$ minute ventilation (VE), (C) VE/maximal voluntary ventilation (MVV), (D) respiratory rate (RR), (E) dyspnoea, and (F) heart rate (HR). The dashed line represents the peak value achieved on the incremental shuttle walk. Values are mean (SE).
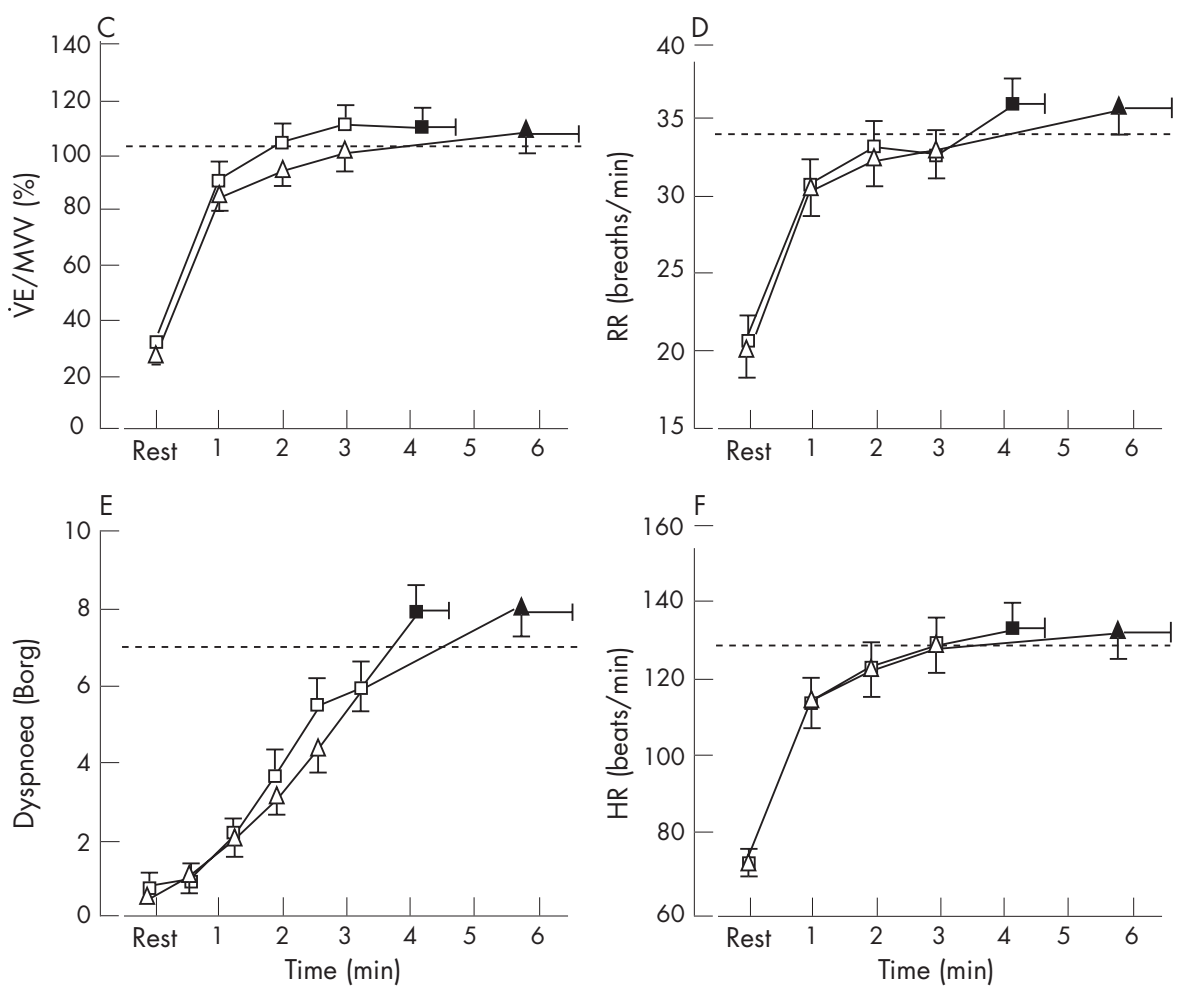

and the endurance shuttle walk-the cardiorespiratory response and the degree of quadriceps muscle fatigue elicited by each test. Previous investigations have shown that the occurrence of contractile fatigue of the quadriceps is much less common after walking tests than after cycling tests. ${ }^{29}$ In the present study, average quadriceps twitch force was maintained after both walking tests and quadriceps muscle fatigue (postexercise fall in twitch force $\geqslant 15 \%$ ) was observed in $<15 \%$ of patients. These findings support the concept that the relative contribution of quadriceps muscle fatigue to walking capacity is small.

Several important observations were made regarding the cardiorespiratory response to both walking tests. First, the initial response was faster during the endurance shuttle walk than during the 6MWT. Minute ventilation, respiratory rate, and heart rate quickly approached maximal values during endurance shuttle walking, while the same three parameters remained at submaximal levels throughout the 6MWT. This probably explains, at least in part, the shorter duration (and walking distance) of the endurance shuttle walk with placebo. Second, cardiorespiratory kinetics and walking speeds were very similar for both $6 \mathrm{MWTs}$, suggesting that patients tend to reproduce the same walking pattern during 6 min walking, whether on placebo or ipratropium bromide. In a previous investigation, Casas and colleagues ${ }^{22}$ reported that the mean walking speed achieved during a 6MWT was highly predictive of critical walking speed, a surrogate of critical power, in patients with COPD. They reported a high concordance between the critical walking speed and the walking speed during the $6 \mathrm{MWT}$, which suggests that patients naturally set their walking speed at the maximal sustainable level. Critical walking speed cannot be estimated from our set of data. However, the mean walking speed during the 6MWT in our patients, which ranged from 1.25 to $1.90 \mathrm{~m} / \mathrm{s}$, was very similar to that achieved by the patients studied by Casas and colleagues, suggesting that our patients were actually walking at their maximum sustainable walking speed. If we accept the idea that critical walking speed is a surrogate of critical power, the results of our study imply that critical power does not change with bronchodilation. Third, the cardiorespiratory response to endurance shuttle walking was also similar between the two testing conditions but, unlike for the 6MWT, this was expected since the workload was imposed and was identical for both conditions. A potential explanation for the improvement in endurance shuttle walking distance with bronchodilation is that, despite a higher peak $\dot{\mathrm{V}}_{2}$ during the ipratropium shuttle walk than the placebo walk, 
dyspnoea at the end of the walk was similar between the two conditions. A reduction in dyspnoea for a given $\dot{\mathrm{V}}_{2}$ could be explained by reduced work of breathing or less dynamic hyperinflation with ipratropium bromide. ${ }^{30}$ This physiological investigation was, however, beyond the scope of the present study. Irrespective of the mechanisms, patients were able to tolerate the same load for a longer time, which translated into improvements in the endurance shuttle walking distance.

Subjective information obtained from patients supported our physiological observations. Most of the patients cited dyspnoea as the main limiting factor for both walking tests (as opposed to leg fatigue or to a combination of dyspnoea and leg fatigue), which supports the notion that leg fatigue is not a prevalent finding after walking tests, whether evaluated objectively or subjectively. Patients rated their dyspnoea higher for the endurance shuttle walk than for the 6MWT, and perceived the endurance shuttle walk to be more demanding than the 6MWT.

Together, our findings pertaining to test duration, cardiorespiratory response and perceived degree of difficulty suggest that the endurance shuttle walk is more physiologically demanding than the 6MWT. Surprisingly, the mean walking speed was similar for both tests. However, the endurance shuttle walk was performed on a $10 \mathrm{~m}$ course while the 6MWT was performed on a $30 \mathrm{~m}$ course. This was done to comply with the guidelines for each test. ${ }^{15}{ }^{17}$ The endurance shuttle walk therefore required that patients change direction much more frequently than the 6MWT. Although a recent multicentre study showed no effect of course length on 6MWD for straight courses ranging from 15 to $50 \mathrm{~m},{ }^{31}$ our physiological and subjective data suggest that the numerous accelerations and decelerations required during the endurance shuttle walk made it more difficult for patients to maintain the same mean walking speed than during the 6MWT.

Although patients perceived the endurance shuttle walk to be demanding, they were able to increase their endurance time with ipratropium bromide and therefore covered more distance. In contrast, patients replicated the same walking pattern for the $6 \mathrm{MWT}$, regardless of the testing condition, and consequently did not increase 6MWD in response to bronchodilation. These findings suggest that it is easier for patients to increase endurance time than it is to increase walking speed, thereby suggesting that the different designs of the tests had an impact on their respective response to bronchodilation. The situation appears to be different in pulmonary rehabilitation, since the 6MWT has been shown to be somewhat responsive in that setting. ${ }^{32}$ One potential explanation is that patients may learn how to walk faster during pulmonary rehabilitation, an effect unlikely to be achieved by acute bronchodilation alone. Nonetheless, improvements in 6MWD after pulmonary rehabilitation have not consistently reached the minimal clinical important difference. ${ }^{32}$ In addition, recent evidence suggests that the endurance shuttle walk is more responsive to the effects of pulmonary rehabilitation than the 6MWT. ${ }^{33}$ The endurance shuttle walk has also recently been shown to discriminate between treatments in short-term studies using altered gas mixtures. ${ }^{34}$ Together, these findings provide growing support for the use of the endurance shuttle walk as an evaluative tool to monitor response to treatment in COPD.

In conclusion, the results of this study indicate that the endurance shuttle walk is more responsive to the acute effects of bronchodilation than the 6MWT. Clinical, physiological and subjective findings suggest that differences in test designs may explain, at least in part, these differences in the responsiveness to bronchodilation. This may be especially true when evaluating patients with COPD with a wide range of disease severity and with a relatively well-preserved functional status. Overall, these findings have important implications for future clinical trials evaluating the functional impact of bronchodilation in patients with COPD.

\section{ACKNOWLEDGEMENTS}

The authors acknowledge the help of Marthe Bélanger, Marie-Josée Breton, Brigitte Jean and Josée Picard in performing this study. They also thank Gaétan Daigle for his statistical assistance and Dr Mike D L Morgan for kindly providing the shuttle walking protocols.

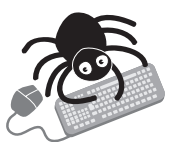

Additional data available online at http:// thorax.bmj.com/supplemental

\section{Authors' affiliations}

Véronique Pepin, Julie Brodeur, Yves Lacasse, Julie Milot, Pierre LeBlanc,

François Whittom, François Maltais, Centre de recherche, Hôpital Laval, Institut Universitaire de Cardiologie et de Pneumologie de l'Université Laval, Québec, Canada

$\checkmark$ Pepin is supported by la Fondation de l'Hôpital du Sacré-Cœur de Montréal. F Maltais is a research scholar of the Fonds de la Recherche en Santé du Québec.

Conflict of interest: None declared

\section{REFERENCES}

1 Global Initiative for Chronic Obstructive Lung Disease. Global strategy for the diagnosis, management, and prevention of chronic obstructive pulmonary disease, 2005.http://www.goldcopd.com

2 Pepin V, Saey D, Whittom $F$, et al. Walking versus cycling: sensitivity to bronchodilation in chronic obstructive pulmonary disease. Am J Respir Crit Care Med 2005;172:1517-22.

3 Saey D, Debigaré R, LeBlanc $P$, et al. Contractile leg fatigue after cycle exercise: a factor limiting exercise in patients with COPD. Am J Respir Crit Care Med 2003; 168:425-30.

4 Oga T, Nishimura K, Tsukino $M$, et al. The effects of oxitropium bromide on exercise performance in patients with stable chronic obstructive pulmonary disease. A comparison of three different exercise tests. Am J Respir Crit Care Med 2000;161:1897-901

5 Mahler DA, Donohue JF, Barbee RA, et al. Efficacy of salmeterol xinafoate in the treatment of COPD. Chest 1999;1 15:957-65.

6 Grove A, Lipworth BJ, Reid P, et al. Effects of regular salmeterol on lung function and exercise capacity in patients with chronic obstructive airways disease. Thorax 1996;51:689-93.

7 Boyd G, Morice AH, Pounsford JC, et al. An evaluation of salmeterol in the treatment of chronic obstructive pulmonary disease (COPD). Eur Respir J 1997; 10:815-21

8 Hansen NC, May O. Domiciliary nebulized terbutaline in severe chronic airways obstruction. Eur Respir J 1990;3:463-4

9 Mohammed AF, Anderson K, Matusiewicz SP, et al. Effect of controlled-release salbutamol in predominantly non-reversible chronic airflow obstruction. Respir Med 1991;85:495-500

10 Evald T, Keittelmann S, Sindrup JH, et al. The effect of inhaled terbutaline on $\mathrm{FEV}_{1}, \mathrm{FVC}$, dyspnoea and walking distance in patients with chronic obstructive lung disease. Respir Med 1992;86:93-6.

11 Jaeschke R, Guyatt GH, Willan A, et al. Effect of increasing doses of beta agonists on spirometric parameters, exercise capacity, and quality of life in patients with chronic airflow limitation. Thorax 1994;49:479-84.

12 American Thoracic Society. Standards for the diagnosis and care of patients with chronic obstructive pulmonary disease (COPD) and asthma. Am Rev Respir Dis 1987; 136:225-44.

13 Quanjer PH, Tammeling GJ, Cotes JE, et al. Lung volumes and forced ventilatory flows. Report Working Party Standardization of Lung Function Tests, European Community for Steel and Coal. Official Statement of the European Respiratory Society. Eur Respir J Suppl 1993:16:5-40.

14 Singh SJ, Morgan MD, Scott S, et al. Development of a shuttle walking test of disability in patients with chronic airways obstruction. Thorax 1992;47:1019-24.

15 Revill SM, Morgan MD, Singh SJ, et al. The endurance shuttle walk: a new field test for the assessment of endurance capacity in chronic obstructive pulmonary disease. Thorax 1999:54:213-22.

16 Guyatt GH, Pugsley S, Sullivan MJ, et al. Effect of encouragement on walking test performance. Thorax 1984;39:818-22.

17 ATS statement: guidelines for the six-minute walk test. Am J Respir Crit Care Med 2002;166:111-7.

18 Borg G. Psychophysical bases of perceived exertion. Med Sci Sports Exerc 1982;14:377-81.

19 Jones B, Kenward MG. Design and analysis of cross-over trials, 2nd ed. New York: Chapman \& Hall, 2003.

20 Troosters T, Gosselink R, Decramer M. Six minute walking distance in healthy elderly subjects. Eur Respir J 1999;14:270-4. 
21 Troosters T, Vilaro J, Rabinovich R et al. Physiological responses to the 6-min walk test in patients with chronic obstructive pulmonary disease. Eur Respir J 2002;20:564-9

22 Casas A, Vilaro J, Rabinovich R, et al. Encouraged 6-min walking test indicates maximum sustainable exercise in COPD patients. Chest 2005; 128:55-61.

23 Connolly CK, Chan NS. Salbutamol and ipratropium in partially reversible airway obstruction. Br J Dis Chest 1987;81:55-61.

24 Hay JG, Stone P, Carter J, et al. Bronchodilator reversibility, exercise performance and breathlessness in stable chronic obstructive pulmonary disease. Eur Respir J 1992;5:659-64.

25 Spence DP, Hay JG, Carter J, et al. Oxygen desaturation and breathlessness during corridor walking in chronic obstructive pulmonary disease: effect of oxitropium bromide. Thorax 1993;48:1145-50.

26 Eiser N, Willsher D, Dore CJ. Reliability, repeatability and sensitivity to change of externally and self-paced walking tests in COPD patients. Respir Med 2003;97:407-14

27 Redelmeier DA, Bayoumi AM, Goldstein RS, et al. Interpreting small differences in functional status: the six-minute walk test in chronic lung disease patients. Am J Respir Crit Care Med 1997;155:1278-82.
28 McDowell I Newell C. Measuring health: a guide to rating scales and questionnaires, 2nd ed. New York: Oxford University Press, 1996.

29 Man WD, Soliman MG, Gearing J, et al. Symptoms and quadriceps fatigability after walking and cycling in chronic obstructive pulmonary disease. Am J Respir Crit Care Med 2003:168:562-7.

30 O'Donnell DE, Lam M, Webb KA. Spirometric correlates of improvement in exercise performance after anticholinergic therapy in chronic obstructive pulmonary disease. Am J Respir Crit Care Med 1999;160:542-9.

31 Sciurba F, Criner GJ, Lee SM, et al. Six-minute walk distance in chronic obstructive pulmonary disease: reproducibility and effect of walking course layout and length. Am J Respir Crit Care Med 2003;167:1522-7.

32 Lacasse $Y$, Wong E, Guyatt GH, et al. Meta-analysis of respiratory rehabilitation in chronic obstructive pulmonary disease. Lancet 1996;348:1115-9.

33 Eaton $\mathrm{T}$, Young $\mathrm{P}, \mathrm{Nicol} \mathrm{K}$, et al. The endurance shuttle walking test: a responsive measure in pulmonary rehabilitation for COPD patients. Chronic Respir Dis 2006;3:3-9.

34 Laude EA, Duffy NC, Baveystock C, et al. The effect of helium and oxygen on exercise performance in chronic obstructive pulmonary disease: a randomized crossover trial. Am J Respir Crit Care Med 2006;173:865-70.

\section{LUNG ALERT}

\section{CT screening helps to detect resectable lung cancers and may improve survival}

$\Delta$ Henschke Cl, Yankelevitz DF, Libby DM, et al. Survival of patients with stage I lung cancer detected on ct screening the international early lung cancer action programme investigators. N Engl J Med 2006;355:1763-71.

T his international uncontrolled prospective study screened 31567 asymptomatic individuals using low dose CT scan between 1993 and 2005. Positive tests were defined on baseline screening as the identification of a least one solid or partly solid non-calcified pulmonary nodule $>5 \mathrm{~mm}$ in diameter, at least one non-solid non-calcified pulmonary nodule $>8 \mathrm{~mm}$ in diameter or a solid endobronchial node; and on annual screening as any new non-calcified nodule. Patients with suspicious lesions underwent investigation with positron emission tomography (PET), biopsy or repeat CT scan. The study identified 484 participants with lung cancer, $412(85 \%)$ of whom had clinical stage I disease with an estimated 10 year survival rate of $88 \%$. Survival rates increased to $92 \%$ in the 302 individuals with stage I cancer who underwent surgical resection within 1 month of diagnosis.

The study is limited by lack of a control group and disease specific mortality as its endpoint, resulting in lead time, length time and over diagnosis bias. The majority of lung cancers detected were found on baseline screening (405) compared with annual CT scan (75) and survival rates are statistically projected rather than true values. CT scan as a primary screening tool is noninvasive with a relative low morbidity, however it yields no information regarding the biological behaviour of the nodule and confirmatory diagnosis requires further invasive procedures. CT scan-based screening programmes may prove difficult to implement within the current National Health Service system in the UK, although this American study demonstrates that it can detect curable cancers.

Helen Liddicoat SHO in Respiratory Medicine, Homerton University Hospital, London, UK; drhliddicoat@hotmail.com 